\title{
Movements Monitoring and Falling Detection Systems for Transient Ischemic Attack Patients Using Accelerometer Based on Internet of Things
}

\author{
$1^{\text {st }}$ Dody Ichwana \\ Dept. of Computer Engineering \\ University of Andalas \\ Padang, Indoensia \\ dody.ichwana@fti.unand.ac.id
}

\author{
$2^{\text {nd }} M$. Arief \\ Dept. of Computer Engineering \\ University of Andalas \\ Padang, Indoensia \\ marief210295@gmail.com \\ $4^{\text {th }}$ Shelvi Ekariani \\ Dept. of Mathemathics \\ University of Andalas \\ Padang, Indonesia \\ sekariani@fmipa.unand.ac.id
}

\author{
$3^{\text {rd }}$ Nefy Puteri \\ Dept. of Computer Engineering \\ University of Andalas \\ Padang, Indoensia \\ nefy.puteri@fti.unand.ac.id
}

\begin{abstract}
One symptom of Transient Ischemic Attack (TIA) or mild stroke is a loss of balance that makes ones easy to fall. The attacks on TIA usually occur in a short time and require immediate medical help. This study aimed to develop movements monitoring system and detector of fall for TIA sufferers using accelerometer and technology of internet of things (IoT) technology. The contribution of this study is to define ten falling movements with a decision tree algorithm. These movements are 1). Not moving, 2). Walking, 3). Standing up, 4). Sitting down, 5). Sitting, falling to the right, 6). Standing, falling towards the right, 7). Sitting- falling to the left, 8). Standing, falling to the left, 9). Sitting, falling to the front, 10). Standing, falling forward. An accelerometer is used to detect patient movement through linear and angular acceleration. The definition of movement and state of falling patients is determined by the decision tree algorithm. When a TIA patient falls, the system will send a notification to the family via the Smartphone application about the location where the patient fell. The IoT concept is applied to build this system. This test uses a test scenario of nine positions and movements of patient. Test results show that the system has detected $81.48 \%$ falls in TIA patients and can send notifications to the patient's family with a response time of 2.65 seconds.
\end{abstract}

Keywords-movement monitoring and fall detection system, accelerometer, Decision Tree algorithm, IoT, Transient Ischemic Attack (TIA)

\section{INTRODUCTION}

Stroke is the second most common disease that causes death in the world [1]. In Indonesia, this disease has became the main killer causing around 328.5 thousand death from 2000 to 2012, and stroke was the leading cause of death [2]. Beside to deadly, stroke also causes permanent disability to sufferers. From 15 million people in the world who suffer from strokes, about 5 million die and 5 million others are permanently disabled [3].

Stroke symptoms that are often experienced by sufferers are arm limp and difficult to talk [4][5]. Also, other symptoms that also often arise are problems in one or both eyeballs, loss of balance in the body, dizziness and headaches without knowing the cause in a short period [5][6]. Symptoms like this indicate that the patient is experiencing TIA (Transient Ischemic Attack) or a mild stroke [6] [7]. Sufferers often ignore mild stroke. Based on surveys from the American Stroke Association and the American Heart Association shows that as many as $25-42 \%$ of stroke patients treat it by allowing the symptoms to disappear, and $31-51 \%$ by taking rest. This disease is a signal of a stroke to sufferers in the future [8][9].

Attacks such as dizziness, loss of body balance, causing the patient to easilly fall. Some sufferers consider this as normal and continue their activities. They, however, must have an immediate medical help in less than 4 hours after a sudden fall in order to reduce the risk of a more severe stroke.

There have been many studies of movement monitoring and fall detection of humans using cameras, floor sensor, infrared sensors, microphones and pressure sensors, but this system has weaknesses regarding efficiency, portability and price compared to using accelerometer sensors $[10][11][12][13][14]$. Monitoring of motion and detection of falls can increase accuracy by $3.1 \%-13.4 \%$ by combining the accelerometer sensor and gyroscope sensor [15]. In [16] [17] falling detection studies has been done using camera depth, Kinect camera and accelerometer, but the monitoring area is limited to the camera range. Some studies have used different methods to detect movements and fall. Most of the studies, however, employ K-NN and HMM methods; ones using decision tree algorithm is still a few [18]. The studies [19] have developed a system for providing information in the form of geographical position via SMS to the nearest family. It also has an alert alarm used for someone who fells. Internet of Things (IoT) technology makes it possible to control and monitor a system through a network, making the system more dinamic $[20][21][22]$.

This study aims to develop a motion and detection monitoring system for TIA sufferers using an android based accelerometer of the technology of internet of things (IoT). The system will detect every movement of TIA sufferers. The system will notify families of TIA sufferers if TIA sufferers fall, making it possible for families to provide help more quickly.

\section{METHODOLOGY}

The system development used in this study is experimental research. The process of system development stages are 1). Problem identification, 2). Needs analysis, 3). System design, 4). System implementation and 5). System testing. In the identification process, the definition of the problem and the subject related to the research is carried out. 


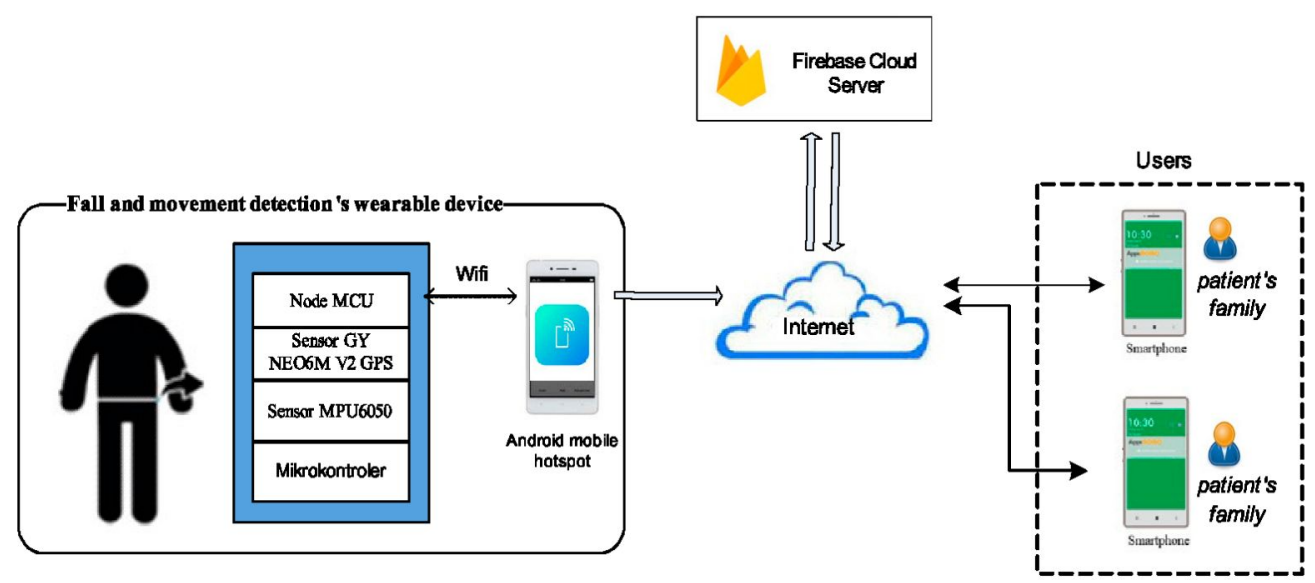

Fig. 1. Architecture of fall and movements detection system

Problem identification is defined by how to monitor the position of TIA sufferers in real time using wearable sensors. Then an analysis of the need to build the system is carried out. In the analysis process, the functional system is determined, namely: a). The system can recognise the activities of TIA sufferers and families can monitor via the Android application, b). The system can find out if a TIA patient falls and immediately sends a notification along with the location of the TIA sufferer who falls to the family through the android application notification. The system design is carried out based on the system needs analysis that has been defined. System design is a description of the system to be built, which consists of two phases: hardware design and software design. Following the system design, implementation is carried out. A system testing process is carried out to determine the level of success of the system that has been created. Testing is carried out with a ten position movement scenario taking into account weight. This system was tested in three volunteers with varying weight: $40 \mathrm{~kg}, 43 \mathrm{~kg}$ and $53 \mathrm{~kg}$.

\section{A. System Design}

In this system, two main components are used. The first device used was a wearable device placed on the waist of a TIA patient. The second device is a smartphone that is used to display the results of monitoring patient movements and notifications if a TIA patient falls. Both of these devices communicate using the internet. Wearable devices are designed using hardware in the form of: a). MPU6050 sensor, an integrated six axis motion tracking device, combines three axis accelerometer and three axis gyroscope. This sensor is used to read linear acceleration and angular movement of sufferers, b). GY NEO6M V2 GPS sensor. This sensor is used to detect the position of the patient by sending data in the form of latitude and longitude, c). NodeMcu, used as a microcontroller that has a Wi-Fi module. Data obtained by the MPU6050 accelerometer sensor is processed by a microcontroller to define the movement of the patient. The GY NEO 6M V2 GPS sensor is used to determine the current patient's position. Movement results that have been defined by the microcontroller and location data are sent to the application server. The patient's family can monitor the movements of TIA patients through an application called MOMO that has been built. The architecture of this system is shown in Figure 1.

Test data collection uses three different subjects with weight variations of $40 \mathrm{~kg}, 43 \mathrm{~kg}$ and $53 \mathrm{~kg}$. Activities used for data collection are a variety of activities consisting of sitting, standing and walking. All activities recorded by censors is ten activities, namely: 1). Not moving, 2). Walk, 3). standing up, 4). Sitting down, 5). Sitting, falling towards the right, 6). Standing, falling towards the right, 7). Sitting, falling toward the left, 8). Standing, falling toward the left, 9). Sitting, falling toward the front, 10). Standing falling forward. Wearable devices are placed on the waist to the right of the subject. Figure 2 shows the position of wearable device monitoring on the subject. Installation of sensors in this position is considered better than some other positions in the human body because it is a part that is close to the centre of gravity of the human body [23].

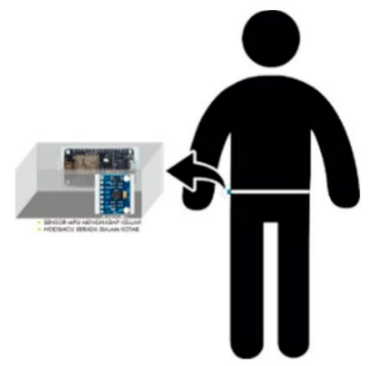

Fig. 2. Wearable sensor device on TIA's patients

\section{B. Movement and Fall Detection Algorithm}

The first step is to initialise the variables that will be used on the system. Furthermore, the accelerometer sensor will detect changes in linear and angular acceleration as a result of motion recording. Calculation of the accelerometer value in MPU6050 sensor has a maximum scale of linear acceleration of $\pm 2 \mathrm{~g}$, the equation used is equation 1 . To get the maximum scale value of $\pm 250 \mathrm{rad} / \mathrm{s}$ at the angular acceleration of the gyroscope sensor that has built on the MPU6050 sensor using equation 2.

$$
\begin{aligned}
& \text { Linear acceleration }=\frac{\text { value of raw data }}{16.384} \\
& \text { Angular acceleration }=\frac{\text { value of raw data }}{131}
\end{aligned}
$$

The next process is to find the resultant of the three axes in the sensor. Resultant for the gyroscope sensor that builds on the MPU6050 sensor uses the Gyroscope X axis, Gyroscope $Y$, Gyroscope Z. For the accelerometer, the definition of movement only requires two axes, namely Accelerometer $\mathrm{X}$ 
and Accelerometer $Z$. However, in programming for training data, we still need value resultant accelerometer. The equation used to determine the resultant gyroscope and accelerometer can be seen in equation 3 and equation 4 .

$$
\begin{aligned}
& R_{G y r o}=\sqrt{G y r o X^{2}+G y r o Y^{2}+G y r o Z^{2}} \\
& R_{A C C}=\sqrt{A c c X^{2}+A c c Y^{2}+A c c Z^{2}}
\end{aligned}
$$

The resultant value of the gyroscope sensor and the value of Accelerometer $\mathrm{X}$ and Accelerometer $\mathrm{Z}$ will be defined as the movement to be understood by the system using the Decision Tree algorithm. This process is carried out on the microcontroller. In Figure 3 it is explained about the program flow that will be processed on the microcontroller.

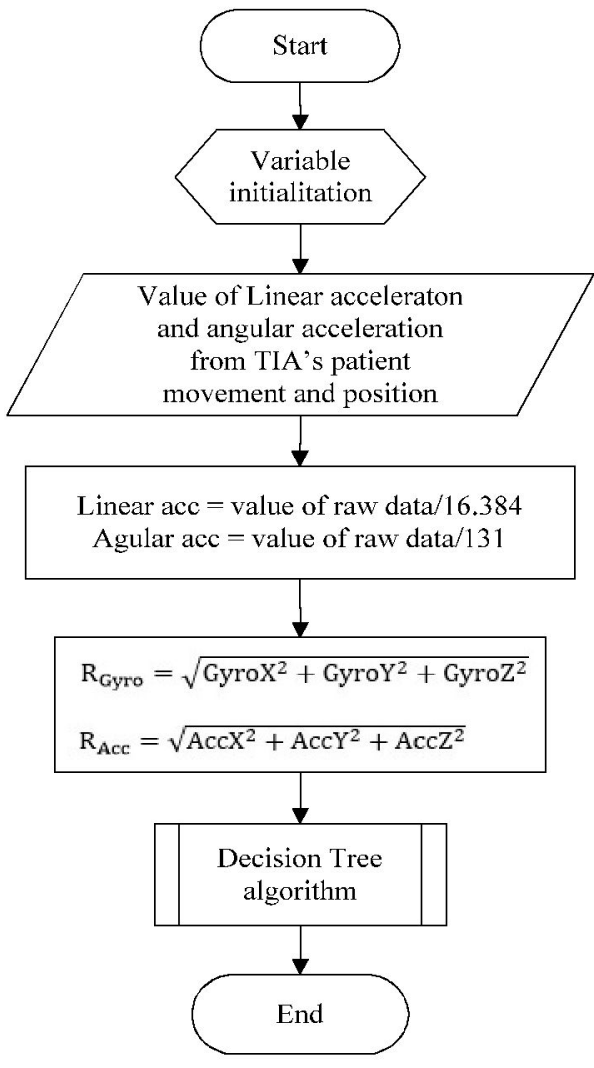

Fig. 3. Programming flowchart on microconttoller

Motion and fall detection algorithm designed in this system using the Decision Tree algorithm with the variables used are: a). $R_{\text {Gyro }}$ is a variable in the form of the resultant value of the angular acceleration $(\mathrm{rad} / \mathrm{s})$ from the calculation of the 3 axis Gyroscope sensor in MPU6050, b). AccX is a linear acceleration value towards the $\mathrm{X}$-axis, c). $A c c Z$ is a linear acceleration value on the $Z$ axis.

This resultant data input is used as a parameter to define a movement. The movement definition will take the form of standing, sitting and walking. Whereas the fall activity is also divided into two major parts, namely, falling perfectly from a sitting position and also falling entirely from a standing position. To fall perfectly from a sitting and standing position will also be classified into falling towards the right, left and front. The training results are used to develop the decision tree algorithm in the form of the definition of movement of TIA sufferers by following the rules in Table I. In Figure 4 the Decision Tree algorithm is shown to detect movement and fall.

TABLE I. DEFINITION OF TIA'S PATIENT MOVEMENT USING THE

\begin{tabular}{|c|c|c|}
\hline No & $\begin{array}{c}\text { Definition of } \\
\text { movement }\end{array}$ & Sensor MPU6050 \\
\hline 1 & Not moving & $\begin{array}{l}\text { If the resultant value of the gyroscope } \\
\text { sensor is }<40 \mathrm{rad} / \mathrm{s}\end{array}$ \\
\hline 2 & Walking & $\begin{array}{l}\text { If the resultant value of the gyroscope } \\
\text { sensor is between } 40 \mathrm{rad} / \mathrm{s} \text { to } 110 \\
\mathrm{rad} / \mathrm{s}\end{array}$ \\
\hline 3 & Standing up & $\begin{array}{l}\text { If the resultant value of the gyroscope } \\
\text { sensor is between } 110 \mathrm{rad} / \mathrm{s} \text { to } 150 \\
\mathrm{rad} / \mathrm{s}\end{array}$ \\
\hline 4 & Sitting down & $\begin{array}{l}\text { The resultant value of the gyroscope } \\
\text { sensor is between } 150 \mathrm{rad} / \mathrm{s} \text { to } 200 \\
\mathrm{rad} / \mathrm{s}\end{array}$ \\
\hline 5 & $\begin{array}{l}\text { Sitting down then } \\
\text { falling to the right }\end{array}$ & $\begin{array}{l}\text { If the resultant value of gyroscope } \\
\text { sensor is }<360 \mathrm{rad} / \mathrm{s} \text { AND } \\
\text { accelerometer value } \mathrm{X}>1.5 \mathrm{~g} \text { AND } \\
\text { accelerometer } \mathrm{Z}<-1.5\end{array}$ \\
\hline 6 & $\begin{array}{l}\text { Standing up then } \\
\text { falling to the right }\end{array}$ & $\begin{array}{l}\text { If the resultant value of gyroscope } \\
\text { sensor is }>360 \mathrm{rad} / \mathrm{s} \text { AND } \\
\text { accelerometer value } \mathrm{X}>1.5 \mathrm{~g} \text { AND } \\
\text { accelerometer } \mathrm{Z}<-1.5\end{array}$ \\
\hline 7 & $\begin{array}{l}\text { Sitting down then } \\
\text { falling to the left }\end{array}$ & $\begin{array}{l}\text { If the resultant resultant result of } \\
\text { gyroscope sensor is }<360 \mathrm{rad} / \mathrm{s} \text { AND } \\
\text { accelerometer } X \text { value }<-1.5 \mathrm{~g} \text { AND } \\
\text { accelerometer } Z>1.5\end{array}$ \\
\hline 8 & $\begin{array}{l}\text { Standing up then } \\
\text { falling to the left }\end{array}$ & $\begin{array}{l}\text { If the resultant resultant result of } \\
\text { gyroscope sensor is }>360 \mathrm{rad} / \mathrm{s} \text { AND } \\
\text { accelerometer } X \text { value }<-1.5 \mathrm{~g} \mathrm{AND} \\
\text { accelerometer } Z>1.5\end{array}$ \\
\hline 9 & $\begin{array}{l}\text { Sitting down then } \\
\text { falling to the forward }\end{array}$ & $\begin{array}{l}\text { If the resultant resultant result of } \\
\text { gyroscope sensor is }<360 \text { rad } / \mathrm{s} \\
\text { AND accelerometer } X \text { value }<-1.5 \mathrm{~g} \\
\text { AND accelerometer } Z<-1.5\end{array}$ \\
\hline 10 & $\begin{array}{l}\text { Standing up then } \\
\text { falling forward }\end{array}$ & $\begin{array}{l}\text { If the resultant resultant result of } \\
\text { gyroscope sensor is }>360 \text { rad } / \mathrm{s} \\
\text { AND accelerometer } X \text { value }<-1.5 \mathrm{~g} \\
\text { AND accelerometer } Z<-1.5\end{array}$ \\
\hline
\end{tabular}
MPU6050 SENSOR

\section{RESULT AND ANALYSIS}

The implementation of this system are the implementation of hardware in wearable devices used by TIA sufferers and the implementation of software on android applications. In Figure 5 is showed the implementation of wearable devices in patients with TIA. The MPU6050 sensor value will be defined as movement using the Decision Tree algorithm by the microcontroller. In this system, NodeMCU which has been integrated with the ESP wifi module is used as microcontroller. Wifi on wearable devices will be connected to mobile hotspot smartphones as a gateway for sending data to the internet server.

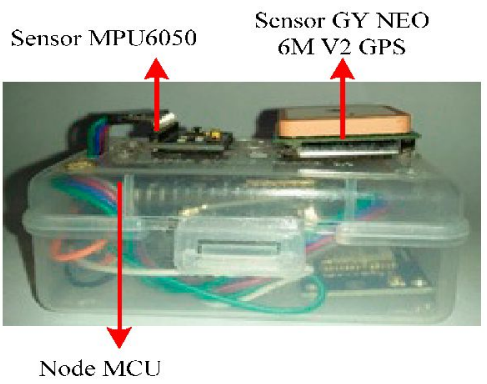

Fig. 4. Wearable device implementation 


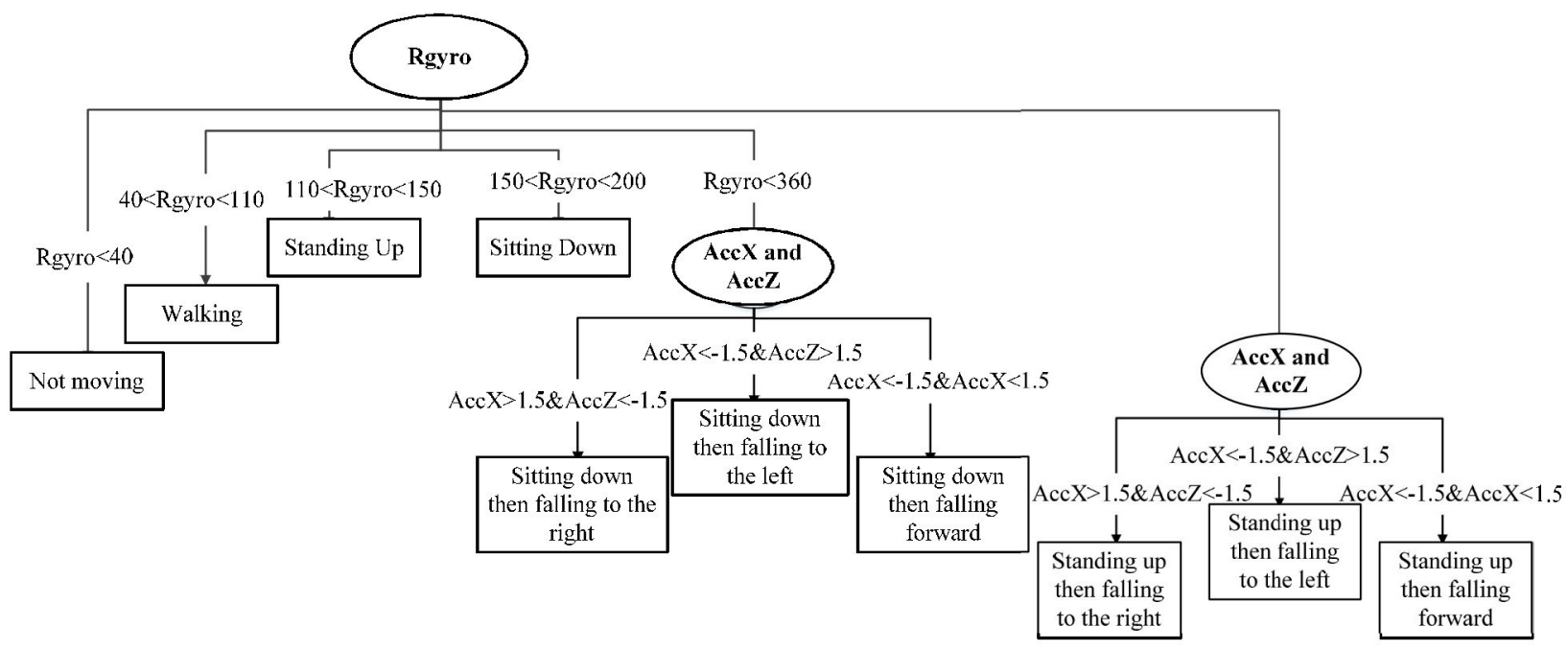

Fig. 5. Decision tree algorithm of movement and fall detection

The definition of movement and the value of GY NEO 6M V2 GPS sensor in the form of latitude and longitude are sent to the firebase storage file. If the patient falls, a notification will appear on the family smartphone which tells that the patient fell from a standing or sitting position and the map will display the location of the patient. If the patient does not fall, in the family smartphone application will appear the activities of TIA sufferers at this time. Figure 6 shows the notification on android application if TIA sufferer falls. In Figure 7 and Figure 8 are showed the monitoring of movement of TIA sufferers through an application on an Android smarthphone that has been built.

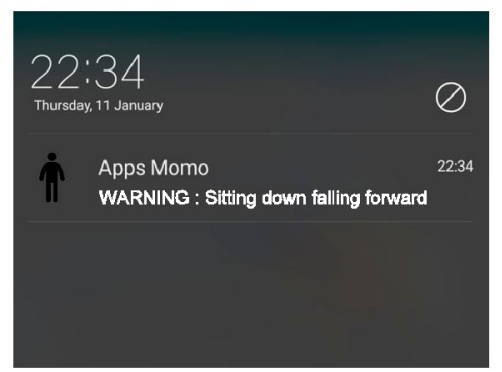

Fig. 6. Warning notification on android application
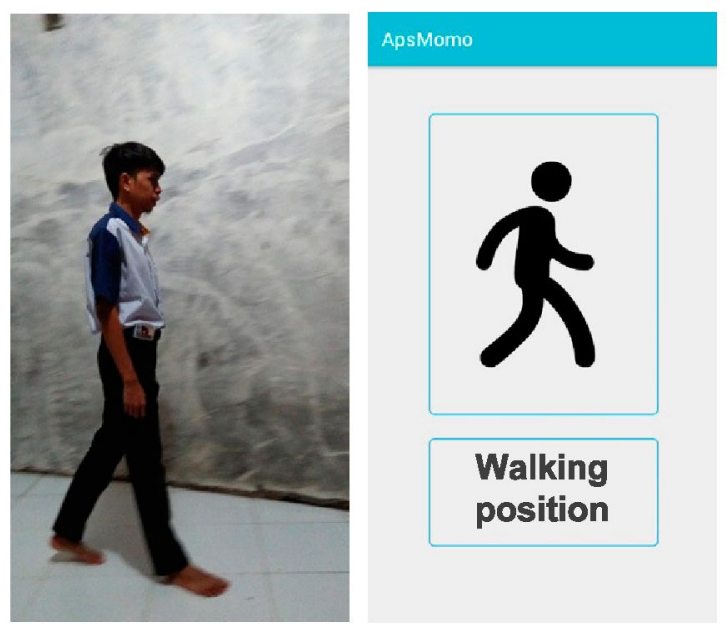

Fig. 7. Monitoring of TIA's patient walking on android application
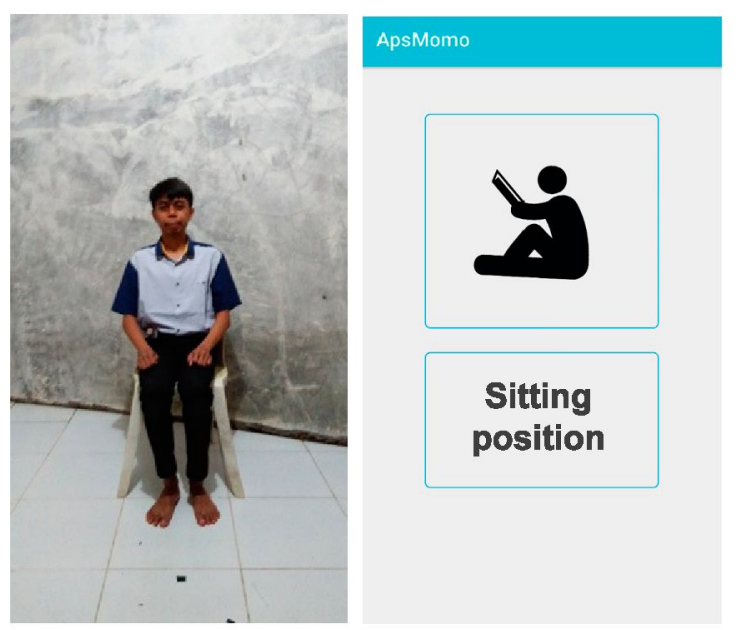

Fig. 8. Monitoring of TIA's patient sitting on android application

Testing the system as a whole using the black box method by providing input data that has been set. This test is carried out using the system usage scenario. Testing is done using a system usage scenario. The test aims to determine the ability of the application and hardware to detect ten human movements that have previously been defined. These movements are: standing, walking, sitting, sit down then fall to the right, sit down then fall to the left, sit down then fall towards the front, stand up then fall to the right, stand up then fall to the left, stand up then fall towards the front. This test was conducted on three volunteers: Volunteer I $(40 \mathrm{~kg})$, Volunteer II (43 kg), and Volunteer II (53 kg). Each volunteer is asked to perform 9 movements which have previously been explained by repeating 5 times for each movement. In Figure 9 (a) is showed a notification given through an application on an Android smartphone when a TIA patient is from a sitting position and falls to the right. Figure 9 (b) is showed the notification given through the application on the Android smartphone when the TIA patient is from a standing position and falls to the left. The results of testing accuracy and the response time needed to detect each movement can be seen in Table II. 
TABLE II. EXPERIMENTAL RESULTS

\begin{tabular}{|l|c|c|c|c|c|}
\hline \multirow{2}{*}{$\begin{array}{c}\text { Positions } \\
\text { category }\end{array}$} & \multirow{2}{*}{$\begin{array}{c}\text { Total } \\
\text { number } \\
\text { of test }\end{array}$} & \multicolumn{2}{c|}{ Succeed } & Accuracy & $\begin{array}{c}\text { Response } \\
\text { Time } \\
\text { (second) }\end{array}$ \\
\hline Standing up & 15 & 15 & 0 & $100 \%$ & 2 \\
\hline Walking & 15 & 15 & 0 & $100 \%$ & 2.13 \\
\hline Sitting down & 15 & 12 & 3 & $80 \%$ & 2.5 \\
\hline $\begin{array}{l}\text { Sitting down then } \\
\text { falling to the right }\end{array}$ & 15 & 12 & 3 & $80 \%$ & 2.83 \\
\hline $\begin{array}{l}\text { Sitting down then } \\
\text { falling to the left }\end{array}$ & 15 & 11 & 4 & $73 \%$ & 2.58 \\
\hline $\begin{array}{l}\text { Sitting down then } \\
\text { falling to the } \\
\text { forward }\end{array}$ & 15 & 8 & 7 & $60 \%$ & 3.11 \\
\hline $\begin{array}{l}\text { Standing up then } \\
\text { falling to the right }\end{array}$ & 15 & 13 & 2 & $86.67 \%$ & 3.07 \\
\hline $\begin{array}{l}\text { Standing up then } \\
\text { falling to the left }\end{array}$ & 15 & 11 & 4 & $73.33 \%$ & 2.73 \\
\hline $\begin{array}{l}\text { Standing up then } \\
\text { falling forwards }\end{array}$ & 15 & 12 & 3 & $80 \%$ & 2.92 \\
\hline
\end{tabular}

Table II is showed the accuracy of movement for nine different movement positions. The highest accuracy is $100 \%$ for standing and walking movements. For lowest accuracy is $60 \%$ for sit then fall to the forward movement. The movement of fall to the back was not done because the safety reasons.
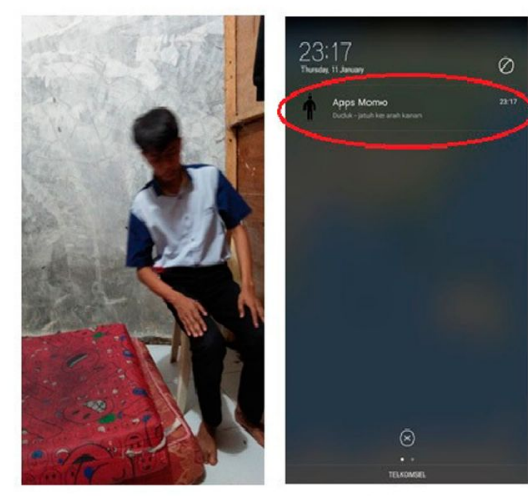

(a)
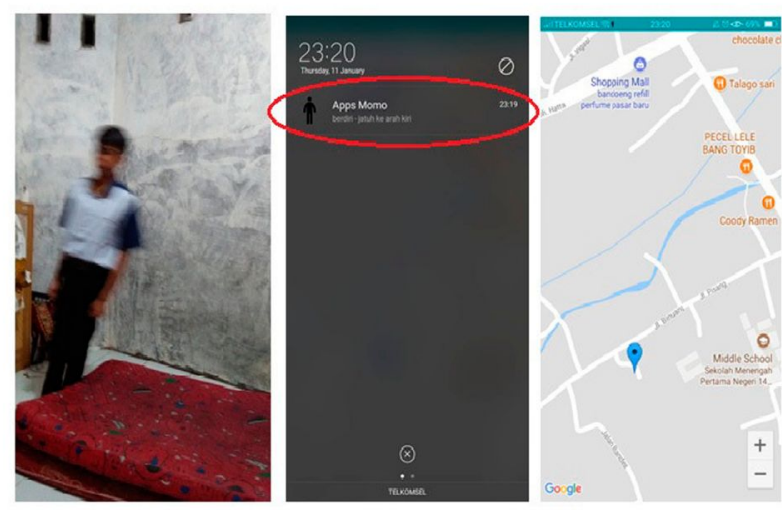

(b)

Fig. 9. Notifications received by users on smartphone android when TIA's patients fall

\section{CONCLuSION}

This research has successfully built and implemented a motion and detection monitoring system for TIA sufferers using an accelerometer through an application running the Android operating system by applying the IoT concept. Decision Tree algorithm used has succeeded in defining the sitting position, standing, walking, and falling to the right, left, and front of a sitting position and standing with a success percentage of $81.48 \%$ with an average response time of 2.65 seconds. This system has also been successful in providing notifications via smartphone along with the patient's geographical position information when it falls to the family. In future work, we will add falling detection for the special condition and using machine learning to detect the movement position in indoor location.

\section{ACKNOWLEDGMENT}

The research is supported by Faculty of Information and Technology, University of Andalas for publication. The authors thank the referee for his/her useful comments and suggestions on the earlier version of this paper.

\section{REFERENCES}

[1] "The top 10 causes of death." [Online]. Available: http: $/ /$ www.who.int/en/news-room/fact-sheets/detail/the-top-10causes-of-death [Accessed: 23-Sep-2018].

[2] Y. Kusuma, N. Venketasubramanian, L. S. Kiemas, and J. Misbach, "Burden of stroke in Indonesia," Int. J. Stroke, vol. 4, no. 5, pp. 379-380, 2009.

[3] "WHO EMRO | Stroke, Cerebrovascular accident|Health topics." [Online]. Available: http://www.emro.who.int/healthtopics/stroke-cerebrovascular-accident/index.html. [Accessed: 24Sep-2018].

[4] J. Misbach, "Stroke di Indonesia : a fisrt large prospective hospital based study of acute stroke in 28 hospitals in Indonesia," J. Clin. Newrosci., vol. 8, no. 3, pp. 245-249, 2009.

[5] "Stroke Warning Signs and Symptoms." [Online]. Available: http://www.strokeassociation.org/STROKEORG/WarningSigns/S troke-Warning-Signs-and-

Symptoms_UCM_308528_SubHomePage.jsp. [Accessed: 24 Sep-2018].

[6] "Stroke Signs and Symptoms | adc.gov." [Online]. Available: https://www.cdc.gov/stroke/signs_symptoms.htm. [Accessed: 24 Sep-2018].

[7] S. Tani et al., "An online support system for stroke education Focusing on use of the system by schoolteachers in junior high schools," Int. Symp. Med. Inf. Commun. Technol. ISMICT, pp. 242-246, 2013.

[8] J. D. Easton et al., "Definition and Evaluation of Transient Ischemic Attack: A Scientific Statement for Healthcare Professionals From the American Heart Association/American Stroke Association Stroke Council; Council on Cardiovascular Surgery and Anesthesia; Council on Cardio," Stroke, vol. 40, no. 6, pp. 2276-2293, 2009.

[9] "Transient Ischemic Attack (TIA)." [Online]. Available: http://www.strokeassociation.org/STROKEORG/AboutStroke/Ty pesofStroke/TIA/Transient-Ischemic-Attack-

TIA_UCM_492003_SubHomePage.jsp. [Accessed: 24-Sep2018].

[10] R. Igual, C. Medrano, and I. Plaza, "Challenges, issues and trends in fall detection systems," Biomed. Eng. Online, vol. 12, no. 66, pp. 1-66, 2013.

[11] T. Xu, Y. Zhou, and J. Zhu, "New Advances and Challenges of Fall Detection Systems: A Survey," Appl. Sci., vol. 8, no. 3, p. 418, 2018.

[12] R. Hegde, B. Sudarshan, S. C. P. Kumar, S. Hariprasad, and B. Satyanarayana, "Technical advances in fall detection system - a 
review," Int. J. Comput. Sci. Mob. Comput, vol. 2, no. July, pp. 152-160, 2013.

[13] N. Pannurat, S. Thiemjarus, and E. Nantajeewarawat, "Automatic fall monitoring: A review," Sensars (Switzerland), vol. 14, no. 7, pp. 12900-12936, 2014.

[14] J. Santiago, E. Cotto, and L. G. Jaimes, "Smartphone-based fall detection system for the elderly," IEEE, pp. 1-4, 2017.

[15] A. Z. Rakhman, L. E. Nugroho, Widyawan, and Kurnianingsih, "Fall detection system using accelerometer and gyroscope based on smartphone," 2014 1st Int. Conf. Inf. Technol. Comput. Electr. Eng. Green Technol. Its Appl. a Better Futur. ICITACEE 2014 Proc., pp. 99-104, 2015.

[16] M. Kepski and B. Kwolek, "Event-driven system for fall detection using body-worn accelerometer and depth sensor," IET Comput. Vis., vol. 12, no. 1, pp. 48-58, 2018.

[17] M. C. Su, J. W. Liao, P. C. Wang, and C. H. Wang, "A smart ward with a fall detection system," Conf. Proc. - 2017 17th IEEE Int. Conf. Environ. Electr. Eng. 2017 1st IEEE Ind. Commer. Power Syst. Eur. EEEIC/I CPS Eur. 2017, pp. 1-4, 2017.

[18] J. He, C. Hu, and X. Wang, "A Smart Device Enabled System for Autonomous Fall Detection and Alert," Int. J. Distrib. Sens. Networks, vol. 2016, 2016.

[19] F. Wu, H. Zhao, Y. Zhao, and H. Zhong, "Development of a wearable-sensor-based fall detection system," Int. J. Telemed. Appl., vol. 2015, 2015.

[20] D. Ichwana and W. Syahputra, "Sistem Pembayaran Parkir Menggunakan NEAR FIELD COMMUNICATION Berbasis ANDROID dan Teknologi INTERNET OF THINGS," J. Teknosi., vol, 03, no. 01, pp. 153-164, 2017.

[21] D. Ichwana, R. Aisuwarya, S. Ardopa, and I. Purnama, "Sistem Cerdas Reservasi dan Pemantauan Parkir pada Lokasi Kampus Berbasis Konsep Internet of Things," J. Teknologi. dan Sist. Komputer., vol. 6, no. 2, p. 57, 2018.

[22] D. Ichwana and D. E. Putra, "Sistem Monitoring Ruangan Ramah Balita pada Smartroom Menggunakan Aplikasi Berbasis Teknologi Internet of Things (IoT)," Semnastek, no. November, pp. 1-2, 2017.

[23] P. Y. M. Chung and G. Y. F. Ng, "Comparison between an accelerometer and a three-dimensional motion analysis system for the detection of movement," Physiother. (United Kingdom), vol. 98, no. 3, pp. 256-259, 2012. 